\title{
Proton Magnetic Resonance Spectroscopy Reveals Medial Temporal Metabolic Abnormalities in Adolescents With History of Preterm Birth
}

\author{
MONICA GIMENEZ, SARA SORIA-PASTOR, CARME JUNQUE, XAVIER CALDU, ANA NARBERHAUS, FRANCESC BOTET, \\ NURIA BARGALLO, CARLES FALCON, AND JOSEP MARIA MERCADER
}

\begin{abstract}
Department of Psychiatry and Clinical Psychobiology [M.G., S.S.-P., C.J., X.C., A.N.], Institut d'Investigacions Biomèdiques August Pi i Sunyer (IDIBAPS) [M.G., S.S.-P., C.J., X.C., A.N., F.B., C.F., J.M.M.], Department of Obstetrics \& Gynecology [F.B.], Radiology Department [N.B., J.M.M.], Department of Physiological Sciences [C.F.], University of Barcelona, Barcelona 08036, Spain
\end{abstract}

\begin{abstract}
Prematurity is associated with volumetric reductions in specific brain areas such as the hippocampus and with metabolic changes that can be detected by spectroscopy. Short echo time (35 $\mathrm{ms})$ Proton magnetic resonance spectroscopy $\left({ }^{1} \mathrm{H} \mathrm{MRS}\right)$ was performed to assess possible medial temporal lobe metabolic abnormalities in 21 adolescents with preterm birth (mean age: 14.8, SD: 1.3) compared with an age-matched control sample (mean age: 14.8, SD: 1.6). ${ }^{1} \mathrm{H}$ MRS spectra were analyzed with linear combination model fitting, obtaining the absolute metabolite concentrations for Creatine (Cr), and myo-inositol (Ins). In addition, the following metabolite sums were measured: total Cho (glycerophospho-choline + phosphocholine), total $N$-acetyl-aspartate $+N$-acetyl-aspartylglutamate (NA), and total Glx (glutamate + glutamine). A stereological analysis was performed to calculate hippocampal volume. Absolute $\mathrm{Cr}$, and total NA values were decreased in the preterm group $(p=0.016 ; p=0.002$, respectively). The preterm also showed a hippocampal reduction $(p<0.0001)$. Significant relationships were found between gestational age and different metabolites and the hippocampal volume. Moreover, hippocampal volume correlated with brain metabolites in the whole sample. Results demonstrate that prematurity affects medial temporal lobe metabolites, and that the alteration is related to structural changes, suggesting that the cerebral changes persist until adolescence. (Pediatr Res 64: 572-577, 2008)
\end{abstract}

$\mathbf{I}_{a}^{n}$ vivo proton magnetic resonance spectroscopy $\left({ }^{1} \mathrm{H} \mathrm{MRS}\right)$ is a neurochemical technique used to investigate specific brain metabolites, which can expand on the structural and functional information obtained by other neuroimaging techniques. Volumetric magnetic resonance imaging (MRI) analyses of subjects with history of preterm birth showed temporal gray matter (GM) reductions (1) and hippocampal changes that persist until the adolescence $(2,3)$.

A previous study reported that preterms evaluated at 40 gestational weeks showed increased $N$-acetyl-aspartate (NAA) compared with the concentrations at birth, and that the levels

Received February 5, 2008; accepted June 18, 2008.

Correspondence: Carme Junqué, Ph.D., Department of Psychiatry and Clinical Psychobiology, University of Barcelona, Institut d'Investigacions Biomèdiques August Pi i Sunyer (IDIBAPS), C/Casanova, 143, CP: 08036 Barcelona, Spain; e-mail: cjunque@ub.edu

Supported by grants from the Ministerio de Ciencia y Tecnología (SAF2005-007340), and the Generalitat de Catalunya (2005 SGR 00855). M.G. and S.S.-P. hold a grant from the Ministerio de Educación, Cultura y Deporte (AP2002-0737 and AP2005-0047, respectively). at the second examination did not differ from those of the full-term control group (4). These data suggest that metabolic decreases in the immature brain may normalize. In addition, a study in adolescents with preterm birth ( $<30 \mathrm{wk}$ of gestation) found a NAA/Cho + Creatine $(\mathrm{Cr})$ reduction in the right temporal lobe in a subsample of preterms $(n=9)$ compared with full-term subjects, suggesting a persistent deficit (5).

No investigations to date have assessed abnormalities in the absolute metabolic concentrations by means of the userindependent frequency domain-fitting program LCModel in a healthy preterm sample at long-term or their relationship with hippocampal volumetric atrophy. The goal of our study was to determine whether single-voxel ${ }^{1} \mathrm{H}$ MRS is able to detect alterations in the medial temporal lobe region in adolescents with preterm birth and normal MRI. We hypothesized that volume reduction of the hippocampus could be related to metabolic abnormalities and that MRI volumetry and spectroscopy could be used as complementary techniques to assess long-term consequences of prematurity.

\section{METHODS}

Subjects. The sample comprised 21 healthy adolescents born prematurely (all $\leq 34$ wk' gestation) and without perinatal complications. Exclusion criteria were: a) history of focal traumatic brain injury; b) cerebral palsy or neurologic diagnosis (including seizure and motor disorders); c) presence of global mental disabilities; and d) antecedents of intraventricular hemorrhages or hypoxic episodes. The preterm group was matched by age to 21 healthy normal gestation controls. All subjects attended normal school. Characteristics of the groups are summarized in Table 1. The study was approved by the ethics committee of the University of Barcelona and by a national research committee. All subjects or their family gave written informed consent before participation in the study. This investigation forms part of a larger project on the long-term consequences of prematurity underway at the University of Barcelona $(3,6,7)$.

Magnetic resonance imaging and spectroscopic acquisition. Data were obtained on a 1.5 Tesla whole body MR scanner (General Electric Signa System; Milwaukee, WI). A set of high-resolution T1-weighted images was acquired with fast spoiled gradient recalled acquisitions with the following parameters: repetition time/echo time $(\mathrm{TE})=12 / 5.2 \mathrm{~ms}$, inversion time 300 $\mathrm{ms} 1 \mathrm{nex}$, field of view $=24 \times 24 \mathrm{~cm}$, and $256 \times 256$ matrix. The

Abbreviations: Cho, choline; Cr, creatine; CSF, cerebral spinal fluid; Glx, glutamate + glutamine; GM, gray matter; ${ }^{\mathbf{1}} \mathbf{H}$ MRS, proton magnetic resonance spectroscopy; ICV, intracranial volume, Ins, myo-inositol; NA, $N$-acetyl-aspartate $+N$-acetyl-aspartylglutamate; NAA, $N$-acetyl-aspartate; TE, echo time, VOI, volume of interest 
Table 1. Characteristics of the sample

\begin{tabular}{lcc}
\hline & $\begin{array}{c}\text { Prematures } \\
\text { Mean } \pm \mathrm{SD}\end{array}$ & $\begin{array}{c}\text { Controls } \\
\text { Mean } \pm \mathrm{SD}\end{array}$ \\
\hline Age (y) & $14.8 \pm 1.3$ & $14.8 \pm 1.6$ \\
Gender (boys/girls) & $8 / 13$ & $11 / 10$ \\
Gestational age (wk) & $30.0 \pm 2.0$ & $40.0 \pm 1.8$ \\
Gestational weight $(\mathrm{g})$ & $1375.4 \pm 348.1$ & $3453.3 \pm 473.8$ \\
\hline
\end{tabular}

whole-brain data were acquired in an axial plane yielding contiguous slices with slice thickness of $1.5 \mathrm{~mm}$.

${ }^{1} \mathrm{H}$ MRS was obtained with a standard quadrature head coil.Proton spectra were obtained from a volume of interest (VOI) of a single $8 \mathrm{~cm}^{3}$ voxel $(2 \mathrm{~cm} \times 2 \mathrm{~cm} \times 2 \mathrm{~cm})$ prescribed from a coronal plane. In all subjects, the VOI was placed on the T1-weighted image in the left medial temporal region, trying to include the hippocampus in all cases. The mid brain cistern was used as the landmark to locate the VOI in all subjects, although in some cases the VOI had to be moved to avoid bone and cerebral spinal fluid (CSF) contamination. This procedure was applied in the same manner in all subjects and care was taken to ensure standard placement. Spectra were acquired with the use of a double-spin echo point-resolved spectroscopy sequence with repetition time $=1500 \mathrm{~ms}$ and $\mathrm{TE}=35 \mathrm{~ms}$, data points 2048 , number of scans 128 , scan time 3 min $48 \mathrm{~s}$, with automatic shimming and water suppression. Point-resolved spectroscopy sequence is a good method for a no-loss sequence if false signals can be minimized at short TE (8). With short TE, metabolites with both short and long T2 relaxation times are observed. Apart from NAA, Cho, and Cr, additional signals can be observed of compounds such as glutamate/glutamine and myo-inositol (Ins) $(9,10)$.

Absolute metabolite quantification: the linear combination model-fitting (LCModel). For the quantification of the absolute concentrations, we used the user-independent frequency domain-fitting program LCModel $(11,12)$ version 6.1-4A, applying an eddy current correction (13) and using internal water signal reference to calculate absolute metabolite concentrations. Finally, to correct the absolute metabolite values we applied the mass of water in the different compartments, assuming that the relative densities of MR-visible water in GM, white matter (WM), and CSF are 0.78, 0.65, and 0.97 (14) respectively. The correction factor used was: "[(GM\% $\times 0.78)+(\mathrm{WM} \% \times$ $0.65)+(\mathrm{CSF} \times 0.97)] /(\mathrm{GM} \%+\mathrm{WM} \%)$ plus use of tissue density of 1.05 $\mathrm{kg} / \mathrm{L}$." Only corrected metabolite concentration values in $\mathrm{mM}$ were used to perform the analyses.

Certain metabolites are quite difficult to resolve from others (12) and the sum of the concentrations of metabolites with similar spectra is much more accurate than the individual concentrations. So, apart from the individual analysis of the $\mathrm{Cr}$ and the Ins compounds, we studied the sum of three pairs: NAA $+N$-acetyl-aspartylglutamate, referred to as "total NA"; glycerophospho-choline + phosphocholine, referred to as "total Cho"; and glutamate + glutamine, referred to as "total Glx". We only considered the metabolite values when the coefficient of variation for the LCModel concentrations was below 20\%, indicating that these metabolites could be reliably estimated (12). For the total Glx, three subjects (two preterm and one control) had a metabolic concentration with a SD $>20 \%$. So, in these cases the values for Glx were discarded. Figure 1 shows an example of the spectra analyzed with the LCModel.

Whole brain tissue segmentation. The values for whole brain GM, WM, and CSF were obtained through the segmentation function using SPM2 software, running in Matlab 6.5 (MathWorks, Natick, MA). We segmented the original brain files obtaining a partition into GM, WM, and CSF for each subject. We obtained a specific value for each tissue in $\mathrm{mm}^{3}$. Intracranial volume (ICV) was calculated by the sum of the three values.

Calculation of the VOI composition. To remove any effect produced by tissue content or CSF contamination in the VOI, we calculated the VOI composition in percentages of GM, WM, and CSF for each subject. The percentages were obtained applying a specific mask including the VOI on each whole brain segmented tissue maps, described above. All the VOI contents are shown in Table 2.

Stereological volumetric analysis. To provide complementary volumetric analysis, we performed stereological measurements of the left hippocampus. Measures were carried out in a Linux workstation, using ANALYZE 6.0 software. First, images were interpolated from $1.5 \mathrm{~mm}$ slices to $0.5 \mathrm{~mm}$ slices to achieve better resolution; a voxel size of $0.5 \mathrm{~mm}^{3}$ was generated. Afterward, images were aligned in accordance with the anterior commissureposterior commissure orientation. The hippocampal volume was measured using a $7 \times 7 \mathrm{~mm}^{2}$ rigid grid with random starting position and angle of deviation from horizontal. The grid was superimposed on every third coronal slice. The coronal orientation was chosen to work with slices oriented perpendicular to the long axis of the hippocampus, a procedure reported to improve measurements (15). The interslice increment and grid size chosen yielded a coefficient of error in the 0.01-0.03 range. The orthogonals tool provided by ANALYZE 6.0 makes it possible to view every grid point in three orthogonal views simultaneously, which helps to decide whether a point is contained by the measured structure or not. With stereology, we can exclude adjacent parahippocampal cortices (see Fig. 2). We obtained direct values from the hippocampal volume in $\mathrm{mm}^{3}$. All stereological measures were corrected by the ICV*100.

Statistical analysis. Metabolic and volumetric data were compared by the $t$ test or by the nonparametric Mann-Whitney $U$ test in the variables that did not fulfill the requirement for parametrical statistical tests.

We performed correlation analyses to relate the gestational age (GA) at birth and the metabolic and volumetric data for the whole sample (by Spearman, because the GA at birth for the whole sample did not fulfill the normality conditions), and separately for patients and controls (by Pearson).

Finally, we performed a correlation analysis (Pearson) in the whole sample relating the metabolic values found different between groups and the hippocampal volume to evaluate the relationship between the hippocampal volume and possible changes in the brain metabolites in this region. All statistical analyses were carried out with the SPSS 14.0 version.

\section{RESULTS}

Magnetic resonance imaging. $\mathrm{T} 1$ visual inspection carried out by two expert neuroradiologists (N.B., J.M.M.) revealed no brain MRI abnormalities in the whole sample. No visual differences were observed in cerebral development in either group.

Whole brain volumetric data. Segmentation analyses revealed that there were no significant differences between groups in GM, WM, CSF, or total ICV (see Table 2).
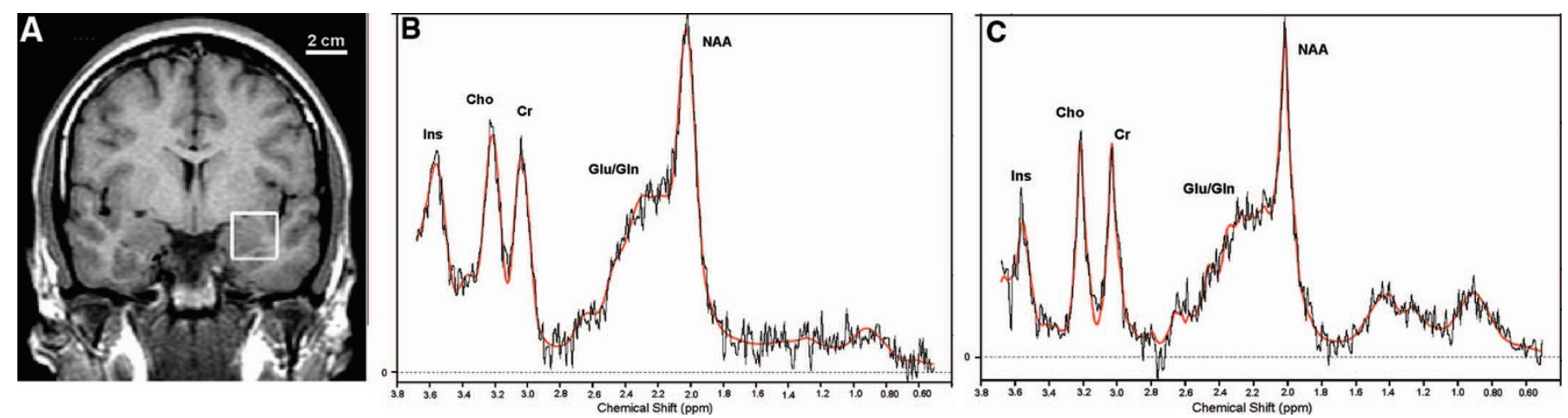

Figure 1. (A) Example of voxel placement. Magnification of the image $\times 0.4 ;(B)$ and $(C)$ proton magnetic resonance spectra with LCModel obtained in the medial temporal lobe in a control $(B)$ and in a preterm subject $(C)$. Acquisition parameters: double-spin echo point-resolved spectroscopy sequence, with repetition time $=1500 \mathrm{~ms}$ and echo time $=35 \mathrm{~ms}$. The values of the chemical shift are provided in parts per million $(\mathrm{ppm})$. 
Table 2. Comparisons of whole brain volumetric data and composition of the VOI between groups

\begin{tabular}{|c|c|c|c|}
\hline & $\begin{array}{c}\text { Preterms } \\
\mathrm{N}=21 \\
\text { Mean } \pm \mathrm{SD}\end{array}$ & $\begin{array}{c}\text { Controls } \\
\mathrm{N}=21 \\
\text { Mean } \pm \text { SD }\end{array}$ & $\begin{array}{l}\text { Statistics } \\
(p \text { value })\end{array}$ \\
\hline \multicolumn{4}{|c|}{ Whole brain volumetric data $\left(\mathrm{dm}^{3}\right)$} \\
\hline Gray matter & $0.77 \pm 0.07$ & $0.80 \pm 0.07$ & $t=-1.282(0.207)$ \\
\hline White matter & $0.38 \pm 0.05$ & $0.40 \pm 0.04$ & $t=-1.562(0.126)$ \\
\hline Cerebral spinal fluid & $0.33 \pm 0.04$ & $0.34 \pm 0.04$ & $t=-0.958(0.344)$ \\
\hline $\begin{array}{l}\text { Total intracranial } \\
\text { volume }\end{array}$ & $1.48 \pm 0.13$ & $1.54 \pm 0.13$ & $t=-1.561(0.126)$ \\
\hline \multicolumn{4}{|c|}{ Percentages of GM, WM and CSF into the VOI } \\
\hline Gray matter & $67.4 \pm 5.9$ & $68.7 \pm 5.9$ & $t=-0.71(0.485)$ \\
\hline White matter & $22.6 \pm 9.3$ & $22.5 \pm 7.4$ & $t=0.01(0.989)$ \\
\hline Cerebral spinal fluid & $10.0 \pm 5.6$ & $8.8 \pm 3.9$ & $t=-0.85(0.401)$ \\
\hline
\end{tabular}

Abbreviations: GM, gray matter; WM, white matter; CSF, cerebral spinal fluid; VOI, volume of interest.

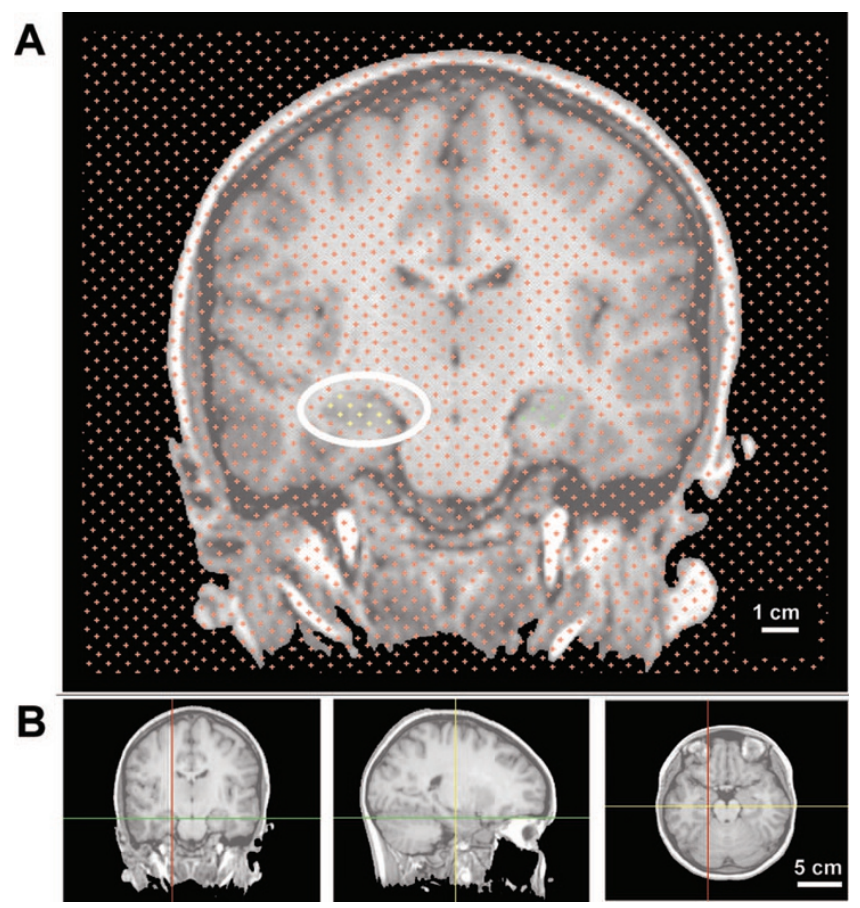

Figure 2. Illustrative stereological grid used for hippocampal measurements. Region of interest is based on a point counting estimation. Only the points inside the structure are considered in the measurements. (A) Circle showing left hippocampal region of interest. Magnification of the image $\times 0.6$. $(B)$ Orthogonal view option in stereology: coronal, sagittal and axial view of the same hippocampal point. Magnification of the image $\times 0.2$.

VOI composition results. We did not find any difference in GM, WM, or CSF contained into the VOI between preterm and full-term adolescents (see Table 2).

Spectroscopy. ${ }^{1} \mathrm{H}$ MRS metabolite concentrations examined are shown in Table 3. The comparison between groups demonstrated that preterm subjects had significantly lower $\mathrm{Cr}$ and total NA levels than the control group. In contrast, no significant differences were found in the total Cho, the Ins or in the total Glx.

In addition, considering that NAA and $\mathrm{Cr}$ showed the most profound effects whereas Cho did not, as a complementary analysis, we calculated the following metabolites ratios: NAA/
Table 3. Between groups comparison of the metabolite concentrations

\begin{tabular}{llll}
\hline & $\begin{array}{c}\text { Preterms } \\
\mathrm{N}=21 \\
\text { Mean } \pm \mathrm{SD}\end{array}$ & $\begin{array}{c}\text { Controls } \\
\mathrm{N}=21 \\
\text { Mean } \pm \mathrm{SD}\end{array}$ & Statistics ( $p$ value) \\
\hline $\begin{array}{c}\text { Metabolite absolute } \\
\text { values (mM) }\end{array}$ & & & \\
Creatine & $3.5 \pm 0.6 \mathbf{6}$ & $4.0 \pm 0.5$ & $t=-2.52(0.016)$ \\
Total Cho & $1.3 \pm 0.3$ & $1.4 \pm 0.2$ & $t=-0.54(0.594)$ \\
Total NA & $4.8 \pm 0.8 \mathbf{6}$ & $5.6 \pm 0.7$ & $t=-3.31(0.002)$ \\
Myo-inositol & $3.9 \pm 1.0$ & $4.4 \pm 0.9$ & $t=-1.90(0.065)$ \\
Total Glx* & $9.1 \pm 1.6$ & $9.2 \pm 1.2$ & $t=-0.23(0.816)$ \\
Metabolite ratio & & & \\
$\quad$ values & & & \\
$\quad$ Creatine/total Cho & $2.7 \pm 0.3 \mathbf{6}$ & $3.0 \pm 0.4$ & $t=-2.60(0.013)$ \\
Total NA/total Cho & $3.7 \pm 0.5 \mathbf{6}$ & $4.2 \pm 0.6$ & $t=-2.60(0.013)$ \\
\hline
\end{tabular}

$* \mathrm{~N}=19$ preterm versus 20 controls.

Abbreviations: Total Cho, Glycerophosphocholine + Phosphocholine; Total NA, $N$-acetyl-aspartate $+N$-acetyl-aspartylglutamate; Total Glx, Glutamate + Glutamine; CSF, cerebral spinal fluid.

6: indicates lower levels of metabolite in comparison with the other group.

Cho and $\mathrm{Cr} / \mathrm{Cho}$. The results showed that the tendency and meaning of the results remain in the same way than those reported in the metabolite absolute value results (see Table 3).

Hippocampal stereology. We found a significant left hippocampal volume loss in the premature group (volumes before standardization) compared with controls $(t=-5.81 ; p<$ 0.0001; preterm (mean $\pm \mathrm{SD}$ ): $2335.5 \mathrm{~mm}^{3}+292.4$; control (mean \pm SD): $2848.1 \mathrm{~mm}^{3}+256.2$ ). After standardization of hippocampal volume by ICV, the hippocampal volume reduction remained statistically significant $(t=-4.07 ; p<$ 0.0001).

Gestational age relationships. Correlations analyses between GA at birth and the metabolic and volumetric data showed a significant positive correlation in the whole sample $(n=42)$ between GA at birth and Cr, total NA, Ins, and the volume of hippocampus (see Table 4 and Fig. 3). In the preterm group, we also observed significant positive correlations between GA at birth and total NA (see Table 4). No other correlations were observed either in the premature group and or in controls.

Hippocampal volume relationships. The study of the relationship between the volumetric data and the metabolite values revealed a significant positive correlation in the whole sample between total NA and hippocampal volume (a high significance with volume before standardization and a trend toward significance with the hippocampal volume corrected by the ICV): that is, the greater the volume of hippocampus, the higher the level of total NA (hippocampal direct values: $r=0.51, p<0.0001$; hippocampal values corrected by ICV: $r=0.31, p=0.053$ ). Moreover, we also found a relationship between $\mathrm{Cr}(r=0.43, p=0.005)$, Ins $(r=0.38, p=0.013)$, and hippocampal volume in direct values.

\section{DISCUSSION}

In this ${ }^{1} \mathrm{H}$ MRS study, we found differences in absolute metabolite concentrations in the medial temporal lobe region between a group of adolescents with history of prematurity 
Table 4. Significant correlations between gestational age and metabolite values and volumetric data

\begin{tabular}{lc}
\hline & Rho spearman $(p)$ \\
\hline Whole sample & \\
Metabolites & $0.37(0.015)$ \\
Creatine & $0.47(0.002)$ \\
Total NA & $0.31(0.049)$ \\
Myo-inositol & $0.64(<0.0001)$ \\
Volumetric data & \\
$\quad$ Hippocampal volume (volume & $0.37(0.018)$ \\
$\quad$ before standardization) & \\
$\quad$ Hippocampal volume corrected by & Pearson $(p)$ \\
$\quad$ the Intracranial volume*100 & \\
Preterm sample & $0.43(0.052)$ \\
Metabolite & Total NA \\
\hline Abbreviations: Total NA $N$-acetyl-aspartate $+N$-acetyl-aspartylglutamate.
\end{tabular}

and a control group. Total NA and $\mathrm{Cr}$ were lower in the preterm sample.

Metabolite concentrations of NA-containing compounds are thought to be localized mainly in mature neurons (16). NAA is a marker for either neuronal loss or cellular dysfunction (17). NAA values are decreased in several types of cerebral diseases $(18,19)$, and depletion in total NA observed in this study can be interpreted as a reflection of neuronal dysfunction or significant neuronal damage (20). No previous studies in adolescent samples with preterm birth and without perinatal complications have been performed, but a study in a child sample with hypoxic-ischemic insults shows similar results (21). One study reported no differences in NAA values in a group of preterm infants compared with controls (4), but the present study did not find a normalization of total NA values at adolescence in the preterm group.
$\mathrm{Cr}$ is a marker of cell energy in neurons and glial cells (22). It has been suggested that low $\mathrm{Cr}$ concentrations in an immature brain may increase susceptibility to brain damage (i.e., because of hypoxic episodes) (23). Cr depletion reported in this investigation agreed with other studies that demonstrated depletion of $\mathrm{Cr}$ in schizophrenic patients with hippocampal reductions (24) and in degenerative brain lesions (25). In addition, the loss of $\mathrm{Cr}$ may be secondary to a reduction in glial proliferation because glial cells have higher $\mathrm{Cr}$ levels than neurons. A previous study (26) showed that $\mathrm{Cr}$ levels in the developing brain reached adolescent values at 4 mo. In our case, the preterm sample did not reach control values at adolescence.

In contrast to our results, a previous investigation found no differences in brain metabolites between a group of preterm infants and a control sample (27). Most subjects in the present sample (19 out of 21 ) have a GA at birth $<32 \mathrm{wk}$, whereas they studied infants with a GA at birth $>32$ wk. Moreover, they assessed the centrum semiovale for white matter, the thalamus, and the occipital GM.

Our preterm sample also showed a reduction in hippocampal volume compared with controls. This is in agreement with previous volumetric studies in adolescent samples $(2,3)$. In the whole sample, the hippocampal volume reductions, like those of the three brain metabolites in the adolescents with preterm birth (total NA, Cr, and Ins), correlated significantly with GA at birth. In the preterm group, total NA also showed a significant correlation with GA. It may indicate that the degree of prematurity is relevant for long-term neurochemical status.

In addition, our finding about correlations between different metabolites and hippocampal volume suggests that ${ }^{1} \mathrm{H}$ MRS studies can be used to complement information about the
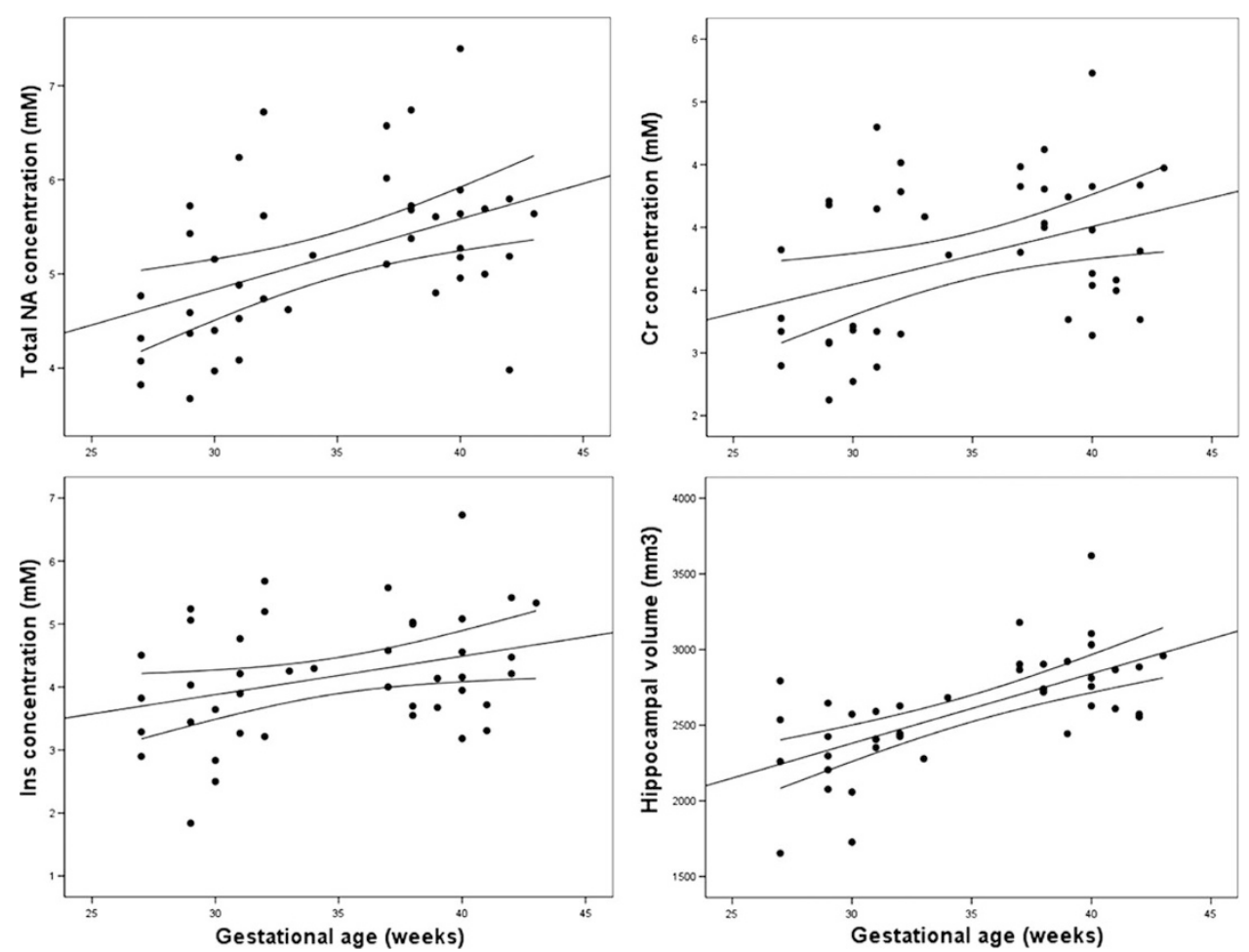

Figure 3. Plots showing corrected metabolic values and the volume of the hippocampus against gestational age. The lines indicate a linear fit to the data, with upper and lower confidence levels (95\%). 
hippocampal integrity. Other studies of temporal pathologies have demonstrated a relationship between metabolic and hippocampal volumetric data $(28,29)$. It is important to take into account that neonatal intensive care exposes preterm neonates to a series of repeated, randomly occurring invasive procedures and handling, resulting in acute pain, chronic pain, and prolonged stress (30). In fact, studies using animal models indicate that perinatal stress has been shown to change NAA concentrations (31). Moreover, $\mathrm{Cr}$ has been reported to protect immature brain from perinatal injury (32) and the fact we showed a relationship between $\mathrm{Cr}$ concentration levels and hippocampal atrophy (the loss of $\mathrm{Cr}$, the reduction in the hippocampal volume) favors this hypothesis.

These differences in neuronal integrity between preterms and controls may be due to several factors, including a possible differential regional vulnerability and disruptions of brain maturation. The medial temporal region has been previously reported to be especially vulnerable in preterm children compared with controls (33).

Our sample size of only 21 preterms should be considered in the current study but other technical aspects can also be mentioned. Only the left medial temporal brain region was evaluated in this study, but it is possible that other regions that have structural deficits in preterm subjects such as thalamus $(3,7)$ or caudate nucleus (34) may present biochemical evidence of neuronal dysfunctions at adolescence. Moreover, we cannot ensure that the entire hippocampus was included in all cases, because we used the visual inspection to avoid the inclusion of CSF of the ventricular system. More recent procedures allow isolating the hippocampus by using the coordinates from three planes (35). However, since relative tissue content can affect both metabolite levels and water intensity used for quantification (14), we studied the VOI composition in the current sample and no differences in GM, WM, or CSF were found between groups. Other studies have primarily used single-voxel approaches to obtain magnetic resonance spectra from the temporal lobe and some investigations support the use of single-voxel spectroscopy for reproducibility in studies of the medial temporal lobe metabolic characteristics $(36,37)$. Regarding the left-right question, an in vivo short $\mathrm{ET}{ }^{1} \mathrm{H}$ MRS study demonstrated that there were no significant left-right differences in the study of the temporal lobe metabolites in normal subjects (38).

This study is the first to demonstrate neurochemical alterations in adolescents with history of prematurity without perinatal complications and normal standard MRI. Consistent with previous spectroscopy findings in preterm adolescents (5), we found decreased metabolite levels in the medial temporal lobe. These changes may provide support for either neuronal dysfunction or neuronal loss and may be associated with reduced neuronal integrity. In addition, these ${ }^{1} \mathrm{H}$ MRS findings were related to the hippocampal volume. This study suggests a possible abnormality in brain metabolism in the medial temporal lobe in preterm that persists until adolescence. Although we found neurochemical differences in preterm adolescents compared with controls, these differences were apparently not relevant for daily living, since our subjects received a normal schooling. Therefore, the functional implications of neurochemical changes require further investigation.

\section{REFERENCES}

1. Kesler SR, Ment LR, Vohr B, Pajot SK, Schneider KC, Katz KH, Ebbitt TB, Duncan CC, Makuch RW, Reiss AL 2004 Volumetric analysis of regional cerebral development in preterm children. Pediatr Neurol 31:318-325

2. Nosarti C, Al-Asady MH, Frangou S, Stewart AL, Rifkin L, Murray RM 2002 Adolescents who were born very preterm have decreased brain volumes. Brain 125:1616-1623

3. Gimenez M, Junque C, Narberhaus A, Caldu X, Salgado-Pineda P, Bargallo N, Segarra D, Botet F 2004 Hippocampal gray matter reduction associates with memory deficits in adolescents with history of prematurity. Neuroimage 23:869-877

4. Huppi PS, Schuknecht B, Boesch C, Bossi E, Felblinger J, Fusch C, Herschkowitz N 1996 Structural and neurobehavioral delay in postnatal brain development of preterm infants. Pediatr Res 39:895-901

5. Isaacs EB, Lucas A, Chong WK, Wood SJ, Johnson CL, Marshall C, VarghaKhadem F, Gadian DG 2000 Hippocampal volume and everyday memory in children of very low birth weight. Pediatr Res 47:713-720

6. Gimenez M, Junque C, Vendrell P, Caldu X, Narberhaus A, Bargallo N, Falcon C, Botet F, Mercader JM 2005 Hippocampal functional magnetic resonance imaging during a face-name learning task in adolescents with antecedents of prematurity. Neuroimage 25:561-569

7. Gimenez M, Junque C, Narberhaus A, Botet F, Bargallo N, Mercader JM 2006 Correlations of thalamic reductions with verbal fluency impairment in prematures. Neuroreport 17:463-466

8. Hofmann L, Slotboom J, Jung B, Maloca P, Boesch C, Kreis R 2002 Quantitative 1H magnetic resonance spectroscopy of human brain: Influence of composition and parameterization of the basis set in linear combination model-fitting. Magn Reson Med 48:440-453

9. Soher BJ, Young K, Govindaraju V, Maudsley AA 1998 Automated spectral analysis III: application to in vivo proton MR spectroscopy and spectroscopic imaging. Magn Reson Med 40:822-831

10. Zhong K, Ernst T 2004 Localized in vivo human 1H MRS at very short echo times. Magn Reson Med 52:898-901

11. Provencher SW 1993 Estimation of metabolite concentrations from localized in vivo proton NMR spectra. Magn Reson Med 30:672-679

12. Provencher SW 2001 Automatic quantitation of localized in vivo $1 \mathrm{H}$ spectra with LCModel. NMR Biomed 14:260-264

13. Klose U 1990 In vivo proton spectroscopy in presence of eddy currents. Magn Reson Med 14:26-30

14. Gasparovic C, Song T, Devier D, Bockholt HJ, Caprihan A, Mullins PG, Posse S, Jung RE, Morrison LA 2006 Use of tissue water as a concentration reference for proton spectroscopic imaging. Magn Reson Med 55:1219-1226

15. Sheline YI, Wang PW, Gado MH, Csernansky JG, Vannier MW 1996 Hippocampal atrophy in recurrent major depression. Proc Natl Acad Sci USA 93:3908-3913

16. Urenjak J, Williams SR, Gadian DG, Noble M 1992 Specific expression of $\mathrm{N}$-acetylaspartate in neurons, oligodendrocyte-type- 2 astrocyte progenitors, and immature oligodendrocytes in vitro. J Neurochem 59:55-61

17. Demougeot C, Garnier P, Mossiat C, Bertrand N, Giroud M, Beley A, Marie C 2001 $\mathrm{N}$-Acetylaspartate, a marker of both cellular dysfunction and neuronal loss: its relevance to studies of acute brain injury. J Neurochem 77:408-415

18. Bertolino A, Weinberger DR 1999 Proton magnetic resonance spectroscopy in schizophrenia. Eur J Radiol 30:132-141

19. Farchione TR, Moore GJ, Rosenberg DR 2002 Proton magnetic resonance spectroscopic imaging in pediatric major depression. Biol Psychiatry 52:86-92

20. Block W, Träber F, Flacke S, Jessen F, Pohl C, Schild H 2002 In-vivo proton MR-spectroscopy of the human brain: Assessment of $N$-acetylaspartate (NAA) reduction as a marker for neurodegeneration. Amino Acids 23:317-323

21. Barkovich AJ, Baranski K, Vigneron D, Partridge JC, Hallam DK, Hajnal BL, Ferriero DM 1999 Proton MR spectroscopy for the evaluation of brain injury in asphyxiated, term neonates. AJNR Am J Neuroradiol 20:1399-1405

22. Wyss M, Kaddurah-Daouk R 2000 Creatine and creatinine metabolism. Physiol Rev 80:1107-1213

23. Holtzman D, Togliatti A, Khait I, Jensen F 1998 Creatine increases survival and suppresses seizures in the hypoxic immature rat. Pediatr Res 44:410-414

24. Maier M, Ron MA, Barker GJ, Tofts PS 1995 Proton magnetic resonance spectroscopy: an in vivo method of estimating hippocampal neuronal depletion in schizophrenia. Psychol Med 25:1201-1209

25. Chang L, Ernst T, Tornatore C, Aronow H, Melchor R, Walot I, Singer E, Cornford M 1997 Metabolite abnormalities in progressive multifocal leukoencephalopathy by proton magnetic resonance spectroscopy. Neurology 48:836-845

26. Toft PB, Leth H, Lou HC, Pryds O, Henriksen O 1994 Metabolite concentrations in the developing brain estimated with proton MR spectroscopy. J Magn Reson Imaging 4:674-680

27. Kreis R, Hofmann L, Kuhlmann B, Boesch C, Bossi E, Huppi PS 2002 Brain metabolite composition during early human brain development as measured by quantitative in vivo $1 \mathrm{H}$ magnetic resonance spectroscopy. Magn Reson Med 48:949-958

28. Sawrie SM, Martin RC, Knowlton R, Faugth E, Gilliam F, Kuzniecky R 2001 Relationships among hippocampal volumetry, proton magnetic resonance spectroscopy, and verbal memory in temporal lobe epilepsy. Epilepsia 42:1403-1407 
29. Schuff N, Amend DL, Knowlton R, Norman D, Fein G, Weiner MW 1999 Age-related metabolite changes and volume loss in the hippocampus by magnetic resonance spectroscopy and imaging. Neurobiol Aging 20:279-285

30. Anand KJ 2000 Effects of perinatal pain and stress. Prog Brain Res 122:117-129

31. Poland RE, Cloak C, Lutchmansingh PJ, McCracken JT, Chang L, Ernst T 1999 Brain $N$-acetyl aspartate concentrations measured by H MRS are reduced in adult male rats subjected to perinatal stress: preliminary observations and hypothetical implications for neurodevelopmental disorders. J Psychiatr Res 33:41-51

32. Berger R, Middelanis J, Vaihinger HM, Mies G, Wilken B, Jensen A 2004 Creatine protects the immature brain from hypoxic-ischemic injury. J Soc Gynecol Investig 11:9-15

33. Peterson BS, Vohr B, Staib LH, Cannistraci CJ, Dolberg A, Schneider KC, Katz KH, Westerveld M, Sparrow S, Anderson AW, Duncan CC, Makuch RW, Gore JC, Ment LR 2000 Regional brain volume abnormalities and long-term cognitive outcome in preterm infants. JAMA 284:1939-1947
34. Nosarti C, Allin MP, Frangou S, Rifkin L, Murray RM 2005 Hyperactivity in adolescents born very preterm is associated with decreased caudate volume. Biol Psychiatry 57:661-666

35. Rademaker KJ, Rijpert M, Uiterwaal CS, Lieftink AF, van Bel F, Grobbee DE, de Vries LS, Groenendaal F 2006 Neonatal Hydrocortisone treatment related to $1 \mathrm{H}$ MRS of the hippocampus and short-term memory at school age in preterm born children. Pediatr Res 59:309-313

36. Traber F, Block W, Freymann N, Gur O, Kucinski T, Hammen T, Ende G, Pilatus U, Hampel H, Schild HH, Heun R, Jessen F 2006 A multicenter reproducibility study of single-voxel (1)H MRS of the medial temporal lobe. Eur Radiol 16:1096-1103

37. Hammen T, Stadlbauer A, Tomandl B, Ganslandt O, Pauli E, Huk W, Neundorfer B, Stefan H 2005 Short TE single-voxel 1H MR spectroscopy of hippocampal structures in healthy adults at 1.5 Tesla-how reproducible are the results? NMR Biomed 18:195-201

38. McLean MA, Woermann FG, Simister RJ, Barker GJ, Duncan JS 2001 In vivo short echo time $1 \mathrm{H}$ magnetic resonance spectroscopic imaging (MRSI) of the temporal lobes. Neuroimage 14:501-509 